\title{
Pensamento crítico e as populações do campo, da floresta, das águas e... das cidades
}

\section{Critical thinking and rural populations, forest, water and cities...}

\section{Pensamiento crítico y las poblaciones del campo, del bosque, de las aguas y... de las ciudades}

Virgínia FONTES ${ }^{1}$

Ary Carvalho de MIRANDA²

Perfilamo-nos integralmente à necessidade da afirmação, da permanente construção e da urgente socialização de uma ciência crítica e emancipadora, intuito tanto mais desafiante quanto mais se expande o capitalismo na atualidade. Esta expansão é o ponto de partida deste brevíssimo ensaio. Durante as últimas décadas, um termo se tornou corriqueiro: crise, muitas vezes adjetivado como "crise do capital". É certo que extensas faixas populacionais vivem situações de crises as mais diversas: alimentar, de saúde, de habitação, de empregos, ambiental, etc.; é certo também que importante crise "econômica" abateu-se em 2008 sobre enormes grupos capitalistas. Porém, enquanto milhares perdiam suas casas nos Estados Unidos ou na Espanha, as grandes empresas desses países escaparam por jorros de recursos provenientes do aprofundamento de gigantescas dívidas públicas, recursos distribuídos a empresas e empresários "grandes demais para quebrar”3.

É preciso sempre relembrar que as crises constitutivas da dinâmica capitalista não indicam sua "fragilidade" nem conduzem automaticamente à sua superação, a qual depende do claro engajamento social no aprendizado e nas lutas contra essa forma de sociabilidade.

Chamemos de crise "econômica" aquelas umbilicalmente ligadas às contradições internas da expansão do capital e que, portanto, ameaçam de maneira imediata a sua reprodução ampliada e 1 Virgínia Fontes é historiadora e professora dos Programas de Pós-Graduação em História (UFF) e do Mestrado Profissional da Escola Politécnica de Saúde Joaquim Venâncio-EPSJV da Fundação Oswaldo Cruz-Fiocruz. Campus da UFF - Gragoatá - Bloco O - 5º andar, São Domingos. CEP: 24210350 - Niteroi, RJ - Brasil.

2 Ary C. Miranda é médico, doutor em ciências, professor do Centro de Estudos da Saúde do Trabalhador e Ecologia Humana, da Escola Nacional de Saúde Pública-ENSP, da Fiocruz. Ambos integram a Coordenação Político-Pedagógica do Mestrado Profissional em Trabalho, Saúde, Ambiente e Movimentos Sociais, ENSP-Fiocruz/Escola Nacional Florestan Fernandes (MST).

3 No século XIX, Marx assinalava ironicamente que "a dívida pública, isto é, a alienação do Estado - seja ele despótico, constitucional ou republicano - imprime sua marca sobre a era capitalista. A única parte da assim chamada riqueza nacional que realmente integra a posse coletiva dos povos modernos é... sua dívida pública." Marx,K. O Capital. SP: Boitempo, 2013, p. 824, grifos nossos, VF e AM. E ele não chegou a conhecer a proporção e o gigantismo da escala a que chegariam tais dívidas. 
atemorizam aos capitalistas, independentemente do grau de sofrimento social que provoquem. Afinal, este sofrimento não influi nas inquietações capitalistas, cuja preocupação se expressa de maneira predominantemente "econômica", isto é, sobre o que diz respeito às taxas de crescimento da produção e da lucratividade. Tais crises "econômicas", sejam decorrentes das contradições entre a enorme concentração da propriedade e a crescente socialização das forças produtivas, ou derivem das contradições entre as exigências crescentes de valorizar o valor e as condições naturais e sociais nas quais ocorre a produção, são componentes inerentes às necessidades de acumulação ampliada dessa forma histórica. Sobre a primeira, Marx sustenta sua inexorabilidade demonstrando que a verdadeira barreira da produção capitalista é o próprio capital, uma vez que sua valorização é ao mesmo tempo ponto de partida e de chegada, ou seja, motivo e finalidade da produção. Esta situação gera uma contradição onde o meio, caracterizado pela expansão incondicional da produção, entra em conflito com os fins, a valorização do capital existente.

A segunda forma de crise "econômica", que se superpõe à crise ecológica, emerge das contradições entre as exigências de valorizar o valor a qualquer custo e as condições sociais e naturais nas quais se realiza a produção capitalista. A crise, aqui, não se limita à órbita da superprodução e de suas consequências sobre a busca crescente da valorização do capital, ou seja, da mercadoria, mas diz respeito a fatores relacionados à fruição destrutiva ou fragilizadora do capital sobre o meio ambiente, à infraestrutura urbana, aos sistemas sociais e à própria força de trabalho, todos elementos constitutivos das condições sociais e naturais para a realização da produção. $\mathrm{O}$ aquecimento global, o desflorestamento, os lixos tóxicos, a salinização das águas, a erosão do solo, os conflitos urbanos, as contaminações químicas, etc., que destroem lugares, pessoas e lucros, são fenômenos cujo prejuízo é socializado pelo capital (todos pagam por ele, enquanto apenas alguns lucram), mas também podem gerar custos adicionais ao capital, para superar as limitações que essa situação impõe a seu ímpeto por acumulação infinita. O bombeiro, entretanto, procura apagar o incêndio com gasolina... Novas empresas capitalistas se constituem (o novo "capitalismo verde") para supostamente reduzir tais efeitos devastadores, deixando de lado o fato de que as relações econômicas e sociais que elas perpetuam causarão outras e ainda mais devastadoras crises. $\mathrm{O}$ capitalismo não acaba por si mesmo. As crises econômicas dos últimos 40 anos não significaram uma redução da expansão brutal das bases sociais capitalistas mundo afora ${ }^{4}$.

O que significa expansão das bases sociais capitalistas? Comecemos pelos aspectos mais imediatos. Vemos todos os dias que o capitalismo se exibe como a permanente criação de novas e reluzentes necessidades mercantis, pela aceleração da inovação tecnológica e pela obsolescência acelerada das mercadorias que os trabalhadores produzem, pelo crescimento de empresas monopólicas que açambarcam o planeta, pela expansão da industrialização da agricultura, pela disseminação de automóveis e de shoppings... No âmago dessa dinâmica, sabemos que dinheiro somente se converte em capital por meio de uma relação social peculiar: proprietários adquirem meios de produção e força de trabalho e, do processo de trabalho, extraem mais-valor dos 4 Há honrosas exceções, principalmente sediadas na América Latina, onde se travam lutas importantes para a construção de novas opções, como Cuba, Venezuela e Bolívia, em especial.

// Tempus, actas de saúde colet, Brasília, 8(2), 305-316, jun, 2014.

ISSN 1982-8829 
trabalhadores, mais-valor escamoteado sob a figura do lucro.

Para que tal relação social possa se instaurar, é necessária a existência permanente de trabalhadores. É preciso sublinhar que prossegue aumentando a base sobre a qual se erige a possibilidade direta da existência do capitalismo: a produção incessante de braços aptos, necessitados e disponíveis para vender sua capacidade de trabalho ${ }^{5}$ - logo o trabalho, exatamente essa atividade que nos singulariza, capaz de transformar a natureza, de aprender fazendo, de comunicar experiências, e que nos distingue de tantas outras espécies ${ }^{6}$. A expropriação do povo do campo é condição ainda vigente para a construção de relações sociais capitalistas. Em nossos dias essa expropriação se exacerba sobre gente que resiste bravamente, inclusive por saber o destino que lhe espera, amontoados em cidades iníquas ${ }^{7}$. Iniciado nos primórdios do capitalismo, esse processo prosseguiu incessantemente ao longo dos quatro últimos séculos. Esvaziou primeiro os campos europeus ${ }^{8}$ mas, para rentabilizar a colonização, saqueou a África escravizando trabalhadores que assegurassem a produção das minas e das monoculturas: aqui, nas Américas, onde a terra não havia sido ainda monopolizada e parecia "livre" aos colonizadores, escravizaram o trabalho9. Quando o volume da população expropriada e carente poderia ameaçar a própria organização social europeia, as guerras a dizimaram, enquanto levas e levas de trabalhadores eram expulsos e migraram para as colonias e ex-colônias, carregando uma bagagem pobre e contraditória, feita de necessidade de ganhar a vida, de garra para lutar e enfrentar os que lhes humilhavam e de preconceitos contra os nativos dos países onde eram recebidos...

Desde seu início a expropriação envolveu procedimentos e leituras contraditórias, que em certa medida nublavam a violência social constitutiva do capitalismo. Ela expressou a fuga de servos e sua libertação do jugo de senhores e de párocos locais, que sustentavam a instituição eclesiástica romana, a nobreza e o Estado absolutista. Porém, libertação e expulsão ocorriam simultaneamente e ambas resultaram em massas crescentes de trabalhadores livres disponíveis em cidades europeias. Em seguida, no século XIX e em parcela do século XX, o fenômeno, apresentado como "urbanização", novamente ocultava suas violentas raízes por meio de uma "atração das cidades" que galvanizaria os habitantes dos campos, em busca de salários, de bens de consumo, de conforto e de "cultura". Novas e romantizadas noções de cidade e de campo configurariam-se. O campo seria revestido de uma aura de idílio e colocado como se estivesse fora do tempo, sem trabalho e

5 Não se trata simplesmente de enunciar leis abstratas, mas de compreender o solo real da vida social que subjaz à expansão capitalista, em seu movimento peculiar e contraditório. Marx, no instigante capítulo "A assim chamada Acumulação Primitiva", enfatiza que "a relação capitalista pressupõe a separação entre os trabalhadores e a propriedade das condições da realização do trabalho. Tão logo a produção capitalista esteja de pé, ela não apenas conserva essa separação, mas a reproduz em escala cada vez maior." MARX, O Capital. SP, Boitempo, Livro I, pp. 785-834, grifos nossos, VF e AM.

6 Cf. Marx, K. Manuscritos econômico-filosóficos e outros textos escolhidos. 2a. ed., SP, Abril Cultural, 1978 e Lukacs, G. El trabalho (extraído da Ontologia del Ser Social). Edição coordenada por A. Infranca e M. Vedda, B. Aires, Ediciones Herramienta, 2004.

7 Ver Davis, Mike. Planeta Favela. SP, Boitempo, 2006.

8 Para um histórico da urbanização no mundo, com dados sobre processos e tendências seculares, ver http://www.ined. fr/fichier/t_publication/1174/publi_pdf1_extraits_urbanisation_monde.pdf, (acesso em 18/05/2014).

9 Martins, José de Souza. $O$ cativeiro da terra. $9^{-}$ed., SP, Contexto, 2010.

ISSN 1982-8829

Tempus, actas de saúde colet, Brasília, 8(2), 305-316, jun, 2014// 
sem atropelos, pacífico e bucólico ${ }^{10}$, borrando mais uma vez o violento e constante fundamento social que sustenta a dinâmica capitalista e, em especial, a urgente superação dessa brutal fratura sociometabólica ${ }^{11}$.

Como explicar o que ocorre na atualidade? O ritmo e a extensão da expropriação de produtores diretos, de gente que vive de sua própria produção imediata, exacerba-se ainda mais no mundo contemporâneo e "mundializado", arrancando populações - majoritariamente do grande Sul do planeta - de suas condições tradicionais de vida. Excluídas? Sim, se considerarmos que são extraídas de suas vidas tradicionais. Entretanto, não são socialmente excluídas, e sim incluídas à força nos contingentes de trabalhadores disponíveis ${ }^{12}$. Para uma significativa parcela dessa população, esse desenraizamento equivale ao risco de sua extinção social, moral, histórica, cultural e... até mesmo física. Nesses casos, aprofundam-se extermínios.

Essa violência originária é permanente no capitalismo: aberta ou discreta, armada ou encaminhada pela fome e pela carência, é a violência que reduz seres humanos à pura necessidade; que transfigura imediatamente a liberdade duramente conquistada em subordinação ao mercado. Disseminado desigualmente nos diferentes países e continentes, o fenômeno é apresentado como se resultasse da "natureza humana", ou ainda como se fosse efeito colateral, porém necessário (um remédio "amargo") de uma vaga modernidade, ou, para outros intérpretes, como se resultasse da perversidade de alguns, "excessivamente" gananciosos. É preciso enfrentar tais argumentos de maneira urgente, pois não apenas as proporções de tal expropriação são gigantescas como, ao inverter o quadro demográfico a partir de 2007, quando a maioria da população mundial passou a residir em cidades, ela se volta para expropriar também os já expropriados. Não são apenas as populações que estão no campo que sofrem as violências dessa separação cotidiana e brutal das condições de sua reprodução. Não apenas os que parecem distantes dos "urbanos", aqueles que vivem num "longínquo" campo os que sofrem essa violência, ainda que sobre estes ela esteja se abatendo com uma força descomunal.

As expropriações não apenas se reproduzem, também se ampliam. As populações urbanizadas há longa data defrontam-se com a violência da expropriação característica da expansão capitalista, agora sob novas modalidades: a retirada de direitos vinculados ao exercício do trabalho, doravante exercido inclusive sem contratos; o desaparecimento dos direitos sociais anteriormente conquistados, visível por exemplo no aumento do tempo para as aposentadorias, ampliando a competição da força de trabalho no mercado de trabalho; perceptível também na contínua redução dos direitos à saúde e à educação, que são extorquidos e, em maior ou menor escala, privatizados e convertidos

10 Cf. R. Williams. O campo e a cidade na história e na literatura. SP, cia. Das Letras, 1989.

11 Foster, John Bellamy. A ecologia de Marx: materialismo e natureza. Rio, Civilização Brasileira, 2005. A esse respeito, Foster demonstra exaustivamente a precoce preocupação de Marx com o fosso criado pelo capitalismo nas relações entre humanidade e natureza. Vale ver também a inquietação de Marx e Engels sobre as imensas contradições derivadas da crescente ruptura introduzida entre campo e cidade no manuscrito não publicado em vida dos autores, $A$ Ideologia Alemã. SP, Boitempo. 2007. Também István Mészáros dedica especial atenção ao fenômeno das rupturas sociometabólicas nas relações humanidade e natureza em Para além do Capital. SP, Boitempo, 2003.

12 Fontes, V. "Capitalismo, exclusões e inclusão forçada”. In: Reflexões Im-pertinentes. Rio, Bom Texto, 2005

// Tempus, actas de saúde colet, Brasília, 8(2), 305-316, jun, 2014.

ISSN 1982-8829 
em formas de valorizar o valor. Formatos diversos para o mesmo processo: subordinar o conjunto da população, urbana e rural, às leis do mercado, ainda que não haja "empregos" nem direitos... Resta apenas o trabalho "livre" e vendável no mercado, despojado de toda defesa que o trabalhador possa opor à sua sujeição. O trabalho livre é mais rentável para o capital do que o trabalho cativo, e vale rever o impactante filme de Gillo Pontecorvo, Queimada!, de 1969. Nele, o personagem compara o trabalho cativo à esposa, que exige gastos a vida inteira, enquanto o trabalho livre corresponderia ao uso da prostituta, que só recebe pagamento enquanto é utilizável. Em nada afeta à relação capitalista que o trabalhador seja livre e sem direitos, pois tal condição ainda exacerba a disponibilidade dos seres sociais para o mercado de trabalho, sob quaisquer condições. Prosseguem existindo formas de trabalho compulsório, análogo à escravidão, assim como o trabalho infantil ${ }^{13}$, reafirmando a voracidade do capital sobre a força de trabalho, em sua permanente necessidade de braços.

Infelizmente, nem a atualidade desse processo nem sua violência se esgotam aqui. Paralelamente à expropriação histórica dos camponeses, ocorreria uma forte concentração da propriedade privada, no tocante ao capital em geral e à monopolização da terra. Hoje, em muitos países do mundo, não há mais sequer um palmo de terra verdadeiramente livre, isenta de propriedade. Essa monopolização da terra aprofunda-se velozmente em nossos dias, sob a forma de uma impetuosa concentração da propriedade da terra, em praticamente todos os quadrantes do planeta, mas com maior ênfase no Sul: África, Ásia, América Latina. Essa concentração da propriedade da terra é especialmente dramática no Brasil ${ }^{14}$, onde terras habitadas, porém livres (da propriedade privada), tornaram-se espaço de "fronteira" para a expansão do capitalismo, devastando águas, matas e gente, avançando celeremente na Amazônia.

No bojo dessa crescente concentração da propriedade do capital, expandem-se empresas destinadas a converter o que eram serviços públicos em novas mercadorias, como saúde e educação.

Dentre esses processos de expropriação/concentração, um dos mais graves - e sobre o qual não temos experiências anteriores - é a atual expropriação da quase totalidade da humanidade de elementos que sempre - ao menos até os dias de hoje - integraram o repertório das trocas sociometabólicas, as que ocorrem entre as sociedades e a natureza, assim como expropriação de aspectos fundamentais da própria vida biológica. No primeiro caso, está a disseminação de sementes transgênicas Terminator, capazes de colonizar as sementes nativas. Para além do envenenamento gigantesco que promovem por estarem associadas a agrotóxicos específicos, espargidos em grandes quantidades, e por não sabermos que efeitos os alimentos transgênicos podem ter nos seres humanos e demais seres vivos, elas podem - e tentam fazê-lo - eliminar uma capacidade

13 Ainda esta semana jornal conservador publicou matéria sobre o tema. Ver Spitz, C.; Almeida, C. e Scrivano, R. "Proibido e perigoso: em dois anos, governo flagrou $10 \mathrm{mil} \mathrm{em} \mathrm{trabalho} \mathrm{infantil} \mathrm{insalubre} \mathrm{ou} \mathrm{arriscado".} \mathrm{O} \mathrm{Globo,} \mathrm{Rio,}$ 19/05/2014, p. 15.

14 No Brasil, "os estabelecimentos com menos de 100 ha são cerca de 90\% do total, ocupando uma área de cerca de $20 \%$, ao passo que os com mais de 100 ha são menos de $10 \%$ do total e ocupam cerca de $80 \%$ da área. E este quadro permanece praticamente inalterado nos últimos 50 anos." Alentejano, Paulo. "Questão agrária no Brasil atual: uma abordagem a partir da Geografia”. Revista Terra Livre, v. 36, p. 116-142, 2011. 
que todos os seres humanos sempre tiveram até hoje: fazer germinar as sementes dos alimentos fundamentais da espécie humana, nos diferentes continentes. Trata-se do arroz, do milho, do trigo e da soja, historicamente bases da alimentação fundamental da humanidade, em diferentes quadrantes do planeta. A violência dessa expropriação atinge as raias do impensável, realizada em uma velocidade impressionante, e vem acoplada a uma monopolização tendencial da germinação de tais sementes. Precisamos enfrentar o inimaginável: em breve, nenhum ser humano poderá plantar aquilo que sempre constituiu o fundamento da nossa existência. Terá de pagar o consentimento de algumas poucas companhias monopolizadoras. Terá sido eliminada, em poucos anos, a capacidade da humanidade de relacionar-se de maneira direta, imediata, profunda e nutritiva com a natureza.

No segundo caso, estão inúmeras patentes de vida biológica e humana, cujos usos ainda obscuros assinalam novas formas de expropriação, de monopólio e de extração de valor.

Tudo isto parece contraditório frente ao desemprego que também grassa no mundo. Ora, é preciso limitar-se a uma visão unilateral para não se dar conta de que o aumento de expropriações, ao produzir incessantemente braços adicionais para o trabalho, ao lado da introdução de tecnologias que dispensam força de trabalho, têm como resultado trabalhadores cada vez mais necessitados e, portanto, disponíveis para agir sob quaisquer condições de trabalho. Formalmente livres, em grande parte dos casos, mas sem outras opções para assegurar suas vidas fora do mercado. No ano de 2013, a Organização Internacional do Trabalho constatou que o emprego "vulnerável" (por conta própria ou realizado por familiares auxiliares, sem direitos a salários regulares ou seguridade social) representava $48 \%$ do total do emprego mundial. O emprego informal em alguns países da América Latina, apesar de melhorias experimentadas, segue em torno de 50\%. Em alguns países da Ásia meridional e sul-oriental a informalidade representa até $90 \%$ do total dos empregos ${ }^{15}$.

Todos os elementos deste cenário expressam a lógica internacional marcada pela expansão desigual e combinada do capitalismo. Essa desigualdade se aprofunda no terreno socioambiental, uma vez que as classes dominantes dos países industrializados procuram simultaneamente extorquir internamente seus trabalhadores (por meio da produção de mercadorias de alto valor agregado) e apoderar-se de fontes de matérias-primas em outros países, cujos processos produtivos são geradores de maior impacto socioambiental. A escala da desigualdade internacional parece aprofundar-se, quando mesmo burguesias de países tardiamente industrializados aderem à produção em larga escala de commodities, agravando a injustiça e a desigualdade social, econômica e ambiental.

Os danos socioambientais, ademais de impactarem mais o hemisfério Sul pelas relações econômicas configuradas na mundialização atual do capitalismo, são agravados pela capacidade de regeneração dos ecossistemas às agressões da racionalidade produtiva. Os ecossistemas tropicais detêm alta produtividade devido à abundância de recursos energéticos e de água, além das características de sua biodiversidade, mas a produtividade no longo prazo depende da conservação de suas condições de estabilidade, cujo equilíbrio está relacionado às conexões dos elementos

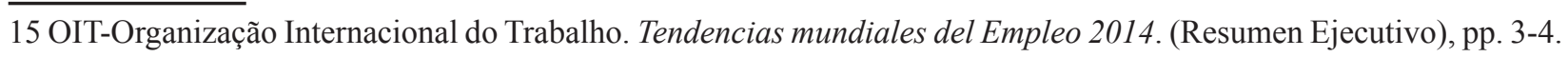
// Tempus, actas de saúde colet, Brasília, 8(2), 305-316, jun, 2014.

ISSN 1982-8829 
físicos e biológicos do meio. Portanto, a regeneração de um ecossistema é tanto maior quanto maiores são seus nichos bióticos e as flutuações, ou seja, uma variada dinâmica metabólica do meio. O desmatamento das florestas, seja para a pecuária ou para a agricultura e, no caso brasileiro, com forte componente monocultor, desestrutura esses equilíbrios fazendo depurar os nutrientes do solo, expondo-o a processos de ressecamento, pela radiação direta do sol, dificultando, assim, a regeneração do ecossistema original.

A exploração dos ecossistemas, fundada na lógica da Revolução Verde - mecanização das relações produtivas com intenso desmatamento, com monoculturas, com a utilização de fertilizantes químicos artificiais e com aplicação de agrotóxicos de forma intensiva e extensiva - se, no primeiro momento, pode alcançar níveis de produtividade alta, gera, ademais de seus efeitos deletérios imediatos, enorme ineficiência, principalmente quando aplicada às zonas tropicais. Como a maior parte do solo desta região é composta de latossolo, tal estratégia produtiva acentua o seu processo natural de lixiviação-laterização, enfraquecendo sua função agrícola.

Vale acrescentar que, na atualidade, aproximadamente $70 \%$ do total de 1 bilhão de pessoas do mundo que têm algum tipo de deficiência alimentar são camponeses, produtores, eles mesmos provedores de alimentos, num momento em que as pressões sobre a terra e os recursos naturais são cada vez mais concretos ${ }^{16}$ Isto ocorre principalmente nas sociedades em que a produção primária tem papel de destaque em sua existência social e econômica.

Nesse contexto, de que conhecimento necessitam as populações do campo e da floresta? Não há dúvida da resposta: necessitam de toda a massa de conhecimento crítico que possamos reunir. Assim como para os trabalhadores das cidades, é urgentíssimo compreendermos que existe uma dinâmica social totalitária, que engloba a maior parte dos aspectos de nossa vida, ditada pelas exigências de reprodução do capital e divulgada como se fosse "natural". Ela é totalitária não apenas por romper nossa relação imediata com a produção da existência, não apenas por necessitar incessante e crescentemente valorizar massas crescentes de valor por meio da extorsão do sobretrabalho, não apenas por alterar nossas condições de vida de maneira violenta e permanente. Ela é totalitária por se capilarizar e atingir todos os poros de nosso tempo e de nossas vidas em todos os continentes; por impor uma "racionalidade" mecânica e unilateral que obtura as contradições e tudo converte em "cálculo". É totalitária também por nos impingir enormes sofrimentos para, em seguida, lucrar com a venda de paliativos. Ela é totalitária ademais por nos fazer crer que é necessária, inescapável e correspondente a uma qualquer "natureza humana", esvaziando a humanidade de sua diversidade, de sua historicidade, de suas possibilidades e de suas condições de luta. Ouso esperar que não sejam definitivas as inúmeras devastações ambientais, sociometabólicas e humanas atualmente em curso.

Enfrentar essa dinâmica social totalitária, que se atualiza na violência diária da expropriação,

16 DELCOURT, L. El Futuro de las Agriculturas Campesinas Ante Las Nuevas Presiones Sobre La Tierra. CETRI, 2012. Disponível em http://www.cetri.be/spip.php?article1952\&lang=es. 
dos salários sem direitos, da conversão de direitos sociais em serviços mercantis, na fetichização da vida e que se justifica através da máquina midiática proprietária, exige simultaneamente explicar e criticar a sociabilidade capitalista em seu formato atual. Exige compreender a forma da expansão generalizada e desigual promovida pelo capital e os efeitos específicos que gera, quer sejam particulares a certos grupos sociais, peculiares a certos setores da população, ou ainda os que incidem com enorme gravidade nos seres, tomados singularmente.

Marx, ao debruçar-se sobre a questão da totalidade, compreendeu que não se exigia saber tudo, mas produzir um conhecimento capaz de enfrentar esse ponto totalitário crucial que tende, sempre contraditória e desigualmente, a "unificar" o planeta sob a égide do capital. A análise crítica que formulou pode ajudar-nos a enfrentar o capitalismo de maneira radical - indo até suas raízes - apesar da escala que esse mesmo capitalismo atingiu. A totalidade marxiana não é, de forma alguma, um olhar desde "fora" ou desde "cima": ao contrário, exige estar com os pés fincados no chão concreto das relações sociais, ali onde os seres de carne e osso constroem sua existência e, dramaticamente, nutrem com seu trabalho uma propriedade do capital cuja concentração nunca foi tão pornográfica e aparentemente tão distante da vida de todos os dias.

Aprofundar a crítica das matrizes de uma ciência potente, porém crescentemente subordinada ao capital, nascida de uma cisão imposta entre os conhecedores e seu próprio mundo histórico e natural, incorporar as exigências da historicidade, do conflito e da territorialidade, socializar a percepção da violência e das imensas contradições que nos cercam é uma exigência de todo e qualquer conhecimento. Superá-la é o intuito, e não simplesmente ignorá-la. Pequenos grupos de intelectuais não podem mais e não serão os responsáveis pelo conhecimento da humanidade: é preciso socializar urgentemente a crítica e o conhecimento já disponíveis para irmos coletivamente além deles. É preciso que todos os militantes contra os agrotóxicos, contra as expropriações, contra o capital possam permanentemente elaborar e reelaborar a crítica da economia política, crítica radical da suposta separação entre economia e vida, realizada por Marx, de maneira a enfrentar as inovações que o capital apresenta, metamorfoseando-se para permanecer o mesmo.

Da mesma forma, é preciso enfrentar o desafio de compreender o que é e como se organizam os Estados na vida contemporânea, assim como as sucessivas reduções impostas às lutas democráticas, tarefa na qual o pensador Antonio Gramsci ainda é referência fundamental. Precisamos retomar a ousadia de nossos clássicos, precisamos reler Marx, Rosa Luxemburgo, Lênin, Trotsky, Gramsci, ainda e desde sempre apresentados como "malditos", sobretudo pelo gume revolucionário de suas ações e de seus textos. Eles não poderão oferecer as soluções que precisamos: precisaremos inventálas nós próprios. Porém, nos ajudarão a pensar em nossas próprias tradições de luta e a consolidar uma reflexão voltada para o mais rigoroso e amplo alcance crítico.

Não basta, entretanto, adquirir um arsenal teórico sem a sensibilidade das condições reais, o que resultaria em mero pedantismo. É preciso unir o compreender e o sentir, a paixão e o saber ${ }^{17}$.

17 Gramsci, A. Cadernos do Cárcere. 2a. ed., Rio, Civilização Brasileira, 2001, vol. 1, p. 221-2.

// Tempus, actas de saúde colet, Brasília, 8(2), 305-316, jun, 2014.

ISSN 1982-8829 
Isso envolve construir permanentemente a compreensão de que temos uma luta em comum, apesar de nossas diferenças. Ela pode nos ajudar a enfrentar o filantropismo que na atualidade embasa as ações das entidades empresariais e que se traduz em teorias pobretológicas (destinada a quantificar pobrezas) que pretendem apagar o processo de produção das desigualdades no mundo real.

O processo histórico se compreende a partir do conflito e das lutas de classes. O pensamento crítico precisa ir além de qualquer visão simplificadora que suponha classes sociais como enormes exércitos homogêneos e claramente demarcados. A análise de Marx permite compreender como as classes sociais estão estreitamente imbricadas na trama da produção geral da vida e da riqueza; permite perceber que as grandes massas, as que produzem toda a riqueza, dela recebem ínfima parcela, proporcional ao lugar que ocupam na distribuição das classes sociais. Se os momentos dos grandes embates são mais raros, a luta de classes ocorre na surdina e no grito do dia a dia.

A matriz de reflexão marxiana é a crítica ao capitalismo e à sua justificação pelas diversas ciências, a começar pela "economia política". Enfatizou tanto elementos objetivos quanto subjetivos, alertando sobretudo para a tendência do capital a alastrar-se e a tudo subordinar. Vemos hoje, mais de um século após sua morte, novas questões e novos problemas resultantes da mesma origem. Parece-nos sempre preciso aprender com nossos clássicos para ir além, enfrentando as novas contradições derivadas da própria expansão do capitalismo, na escala inter e transnacional que hoje imperam, assim como seus rebatimentos no terreno da política ${ }^{18}$.

Para finalizar, vale nos perguntar: o que significa para a humanidade dizimar experiências ancestrais? Marx, em texto clássico, defendia a comuna camponesa russa (mir) como sendo muito mais civilizatória que os "novos pilares" capitalistas que as devastavam"19.

O que se afoga sob inundações para construir hidrelétricas, o que vira cinzas após enormes queimadas, o que se enterra sob monótonas plantações de soja transgênica ou de capim para pasto, ou ainda na mera "reserva de propriedade" de milhares de hectares de terra que, todos eles, envolvem dissolver e eliminar populações?

Já há inúmeros estudos para demonstrar a existência de práticas e de conhecimentos - "saberes" - próprios, ligados a uma outra relação social que envolve lidar com a natureza de maneira diferente desta, predatória, característica do capital. Não são apenas seres humanos (e outros seres vivos) e os conhecimentos que conservaram que desaparecem. Uma grande parcela de nossa própria humanização e das possibilidades de emancipação se esvai. Há uma permanente tendência da vida social sob o capitalismo a apagar, a borrar da história um aprendizado fundamental, o das lutas que enfrentam de múltiplas maneiras a fronteira de expansão do capital. O extermínio de culturas, sociedades e mesmo de grupos sociais é uma maneira de capturar-nos unicamente para 18 Este não é o espaço para apresentar com maior amplitude algumas das recentes características do capitalismo, tratadas anteriormente em Fontes, V. O Brasil e o capital-imperialismo: teoria e história. Rio, 3a. ed., Ed. UFRJ/Ed. EPSJV-Fiocruz, 2012.

19 Marx, K. Projet de réponse à la letre à Véra Zassoulitch,. Oeuvres Choisies, v. 3, Moscou, Ed. Progrès, 1970, pp. 159-168. 
as experiências vividas sob o capitalismo, apagando todas as demais formas que nos mostram que existiram, existem e, por isso mesmo, precisam seguir existindo. Outras formas de viver e de ser para além do capital.

Por essa razão, precisamos assegurar, consolidar e socializar o aprendizado dessas lutas, dessas experiências e disseminá-los por toda a população, dos campos e das cidades, pois essas são também evidências das possibilidades históricas que integram a vida social para aquém e para além dos limites do capital. E. P. Thompson, em belíssimo artigo, lembra que os homens modernos, moldados pelo relógio e pela indústria, "terão de aprender algumas das artes de viver perdidas com a revolução industrial: como preencher os interstícios de seus dias com relações pessoais e sociais mais ricas, mais tranquilas; como romper outra vez as barreiras entre trabalho e vida." ${ }^{20}$

Não se trata de isolar comunidades, de mantê-las numa redoma que as impeça de serem históricas, de se transformarem como todas as sociedades, como sugeriram alguns pós-modernos, mas de aceitar a historicidade própria que produzem, sabendo que ela também nos integra. Não são algo à parte, a ser meramente "conservado" em uma espécie de laboratório a céu aberto, mas parte essencial da vida coletiva da qual somos parcela. Precisamos dessas experiências para enfrentar as contradições de nosso tempo, abrindo a porta para o futuro não apenas imaginado como idealização genérica, mas como resultado real das contradições que atravessam nosso mundo concreto, aqui e agora.

Em importante livro sobre a relação entre as concepções de história e as classes sociais, Josep Fontana, historiador catalão, faz uma breve porém incisiva provocação:

Hay que comenzar a construir, a un tiempo, la nueva historia y el nuevo proyecto social, asentados en una comprensión crítica de la realidad presente. Para lo primero deberemos rehacer nuestra forma de entender el ascenso del capitalismo como un progreso, para aprender a verlo como el desarrollo de una nueva forma de explotación; deberemos volver a explorar tantas alternativas desechadas como utópicas e inviables, para comprobar si acaso no había en ellas planeamientos que apuntaban a otras líneas posibles de evolución. Deberemos tomar en cuenta, sobre todo, que la línea del pasado que proyectemos hacia el futuro hay de apuntar a una sociedad cuyo definidor fundamental no hay de ser el de constituir una fase más avanzada del desarrollo industrial - lo que tampoco implica que haya que rechazar tal desarrollo por principio - , sino la de aproximarnos al ideal de la supresión de todas las formas de explotación del hombre: de una sociedad igualitaria en la que se haya eliminado toda coerción ${ }^{21}$.

Dessa longa citação, gostaríamos de comentar um pequeno trecho, cuja brevidade nem sempre permite a plena compreensão: “devemos voltar a explorar tantas alternativas descartadas como utópicas ou inviáveis, para comprovar se, porventura, nelas não havia colocações que apontavam para outras linhas possíveis de evolução". À sua maneira, Fontana retoma a reflexão de Marx sobre a comuna rural russa. Fiel à compreensão da história como luta de classes, luta expressa também

20 Thompson, E. P. “Tiempo, disciplina y capitalismo”. In. Costumbres en Común. Barcelona, Crítica, 1995, pp. 44950.

21 - Fontana, J. Historia. Análisis del pasado y proyecto social. Barcelona, Crítica, 1982, pp. 11-12.

// Tempus, actas de saúde colet, Brasília, 8(2), 305-316, jun, 2014.

ISSN 1982-8829 
como embate intelectual entre interpretações históricas e entre projetos sociais, Fontana nos solicita retomar o processo histórico, o passado, como algo pleno de lutas dos subalternos. Muitas dessas lutas foram derrotadas e o fio histórico que apontavam foi convertido, pelos grupos dominantes, em utopias ou impossibilidades. Fontana relembra que essas lutas apontavam para possibilidades não realizadas, mas que ainda hoje permanecem fundamentais. Quem sabe mesmo se somente na atualidade tais possibilidades reúnam as condições para se tornar efetivas? A vitória do capitalismo e sua expansão mundial procuram apagar todos os traços de nossas lutas e pretendem nublar suas contradições sob a naturalização de uma "racionalidade" mecânica e absoluta, à qual se acrescenta uma panaceia moralizante enfeitada por um idealismo relativista ${ }^{22}$. Carregamos uma enormidade de histórias e de possibilidades nos desvãos de nossas derrotas, nas cidades e nos campos. Mas, mais do que isso, essas lutas não estão apenas no passado: seguem vivas em nosso presente! Sem retomar os fios de nossas lutas, algumas do passado, outros constitutivas de nosso presente, estaremos limitando nossos horizontes àqueles definidos pelo capital e perdendo exatamente a historicidade crucial que nos apontou Marx.

O contexto que engloba a crise da vida social atual sob o capitalismo impõe-nos enormes desafios para os lineamentos políticos necessários à luta pela sua superação, numa perspectiva alternativa às protelações fomentadas pelos interesses do capital. O maior desses desafios está na formulação dos caminhos teóricos que possam responder às questões inerentes à possibilidade de unificação dos diversos movimentos sociais confrontados às contradições da lógica capitalista, hoje fragmentados e muitas vezes fugazes, no sentido de delinear estratégias que deem perenidade à luta, em suas diversas dimensões, inclusive a luta política. Um desafio é central: o de compreender o papel do trabalho no capitalismo contemporâneo e das possibilidades de atuação da classe trabalhadora. Em primeiro lugar, precisamos avançar na compreensão do significado do mundo do trabalho como elemento fundamental de onde, historicamente, emergiram a tomada de consciência dos trabalhadores, força motriz das expressões organizacionais e políticas que vicejaram e protagonizaram os conflitos sociais de resistência à dominação do capital, do século XIX ao último terço do século XX. Uma verdadeira desarticulação estrutural foi imposta pela reestruturação produtiva, ao lado do aumento do ingresso de trabalhadores disponíveis no mundo, resultado de seguidas expropriações e da acentuada divisão técnica e social do trabalho. Novas desigualdades internas e internacionais foram impostas à classe trabalhadora. Essa desestruturação do mundo do trabalho joga um papel decisivo na alienação do trabalhador, no processo de tomada de consciência e, consequentemente, em sua capacidade de organização e vinculação política de resistência à dominação do capital. Em segundo lugar, precisamos compreender as novas modalidades - desiguais e combinadas - de extração de valor, o que significa também demarcar as formas específicas pelas quais se constroem novas hierarquias no interior da classe trabalhadora, hierarquias lastreadas em graus de conhecimento, em tipos de atividade, em direitos, etc.

Não é um trabalho fácil a fazer. A complexidade de tal empreendimento é enorme, mas esse 22 - Ver, a respeito, Duayer, M. "Anti-realismo e absolutas crenças relativas". Margem Esquerda n. 8, SP, Boitempo, 2006, pp. 109-130. 
é o nosso desafio. A classe trabalhadora é a cada dia mais diversa, díspar e variada, e está nos campos e nas cidades. A luta contra o capital precisa assumir todas as suas cores e, ao reinventar o futuro, tornar-se capaz de criar novas e de atualizar outras tantas possibilidades. Não há como domesticar uma relação social apoiada na expropriação, diretamente baseada na extração de maisvalor e voltada unicamente para valorizar o valor. O conhecimento necessário é, pois, a crítica do mundo real, sua apreensão como forma intelectual, como sensibilidade e como expressão de outra sociabilidade, voltada para a plena socialização da existência. Em todas as suas dimensões. 